\title{
Study on the Airflow Characteristics of the Airfoil Ventilation Fan Based on Coanda Effect
}

\author{
Yaling Ye, Xiaoyong Peng, Yuan Zhang and Hu Wei \\ Urban School of Construction, University of South China, Hunan, Hengyang, 421001, China
}

\begin{abstract}
The airfoil ventilation fan based on Coanda effect was studied, which was simulated by Fluent software. The inducing velocity was considered as an important influence factor on the characteristic of the flow field. The paper reports the results of the velocity distribution in the flow field and the induction rate of the model in different inducing velocities, which shows that with the inducing velocity increasing, the velocity contour develops further and the coverage area becomes larger along the positive $\mathrm{X}$ axis, and the induction rate of airfoil ventilation fan decreases when the inducing velocity reduces and approaching a steady value when the reducing velocity is greater than $25 \mathrm{~m} / \mathrm{s}$. Through the change law of the airfoil inducing rate is explored, the article will give a reference for the choice of inducing velocity in the optimization of the airfoil ventilation fan, and reduce the fan of energy conservation.
\end{abstract}

Keywords-coanda effect; numerical simulation; inducing velocity; ventilation fan

\section{INTRODUCTION}

Coanda effect is also called attaching effect. Flow has a tendency of flowing with the protuberant surface, and the flow speed can slow down if there is friction between the airflow and the object surface that airflow flows. According to Bernoulli principle, as long as the curvature is not very large, the airflow can be attached to the object surface. The effect is named after Henri Coanda, an inventor from romania, which is called Coanda effect [1].

Coanda effect is applied widely in people production and dairy life.In the field of aerospace, Shiyu ZHANG [2] found that the high lift force could be produced by the circulation control airfoil in the situation of zero attack angle, and put forward a low-resistance circulation control airfoil. Longzhe JIN [3] studied the air curtain of the air-knife in avoiding-disaster chamber, analyzed the velocity distribution and got the pressure distribution law around the air-knife.

In the field of civil electrical appliances, James Dyson, an inventor from England, invented the bladeless fan [4], which is still improved continuously until now. Hanxiang WANG [5] had a research on the width and the inclination of outlet in the bladeless fan, analyzed what impact they had and gained their optimal combination.Guangxing ZHANG [6] studied the change law of the flow field in different airfoil curvature and inlet size. The study on the whole bladeless fan has carried out by Guoqi LI [7], including the influence on flow rate, velocity and pressure distribution caused by the splitter blade in different inlet positions and different curvatures, and an optimal combination of bladeless fan.
The research on the airflow characteristic of the airfoil Ventilation Fan is conducted, aiming at exploring the change law of speed distribution and induction rate in different inducing velocity. It can provide a reference for the optimization of the airfoil Ventilation Fan and the choice of the inducing velocity, and reduce the energy consumption of the fan.

\section{PHYSICAL MODELS AND NUMERICAL METHOD}

\section{A. Physical Models}

The airfoil Ventilation Fan based Coanda effect is studied. The 3-D ventilation fan model of $\mathrm{L}=320 \mathrm{~mm}, \mathrm{~W}=240 \mathrm{~mm}$ and $\mathrm{H}=520 \mathrm{~mm}$ is built, and the base size is $320 \mathrm{~mm} \times 240 \mathrm{~mm} \times 150 \mathrm{~mm}$, the inlet size of inducing air is $200 \mathrm{~mm} \times 90 \mathrm{~mm}$ in the base, the air frame size is $200 \mathrm{~mm} \times 300 \mathrm{~mm}$. As shown in the Fig 1(a), the interior of the ventilation fan is consisted of a whole airfoil plate and two half of the airfoil plates, and the size of the whole airfoil plate is $89 \mathrm{~mm} \times 23.5 \mathrm{~mm} \times 200 \mathrm{~mm}$. The width of a narrow slit outlet in the airfoil plates is $1.4 \mathrm{~mm}$, and the height is $200 \mathrm{~mm}$, as shown in the Fig 1(b). The computational domain is a cuboid of $4000 \mathrm{~mm} \times 2000 \mathrm{~mm} \times 2000 \mathrm{~mm}$, the coordinate origin locates in the lowest position of the central axis in the side of the air frame inlet, as shown in the Fig 1(c).

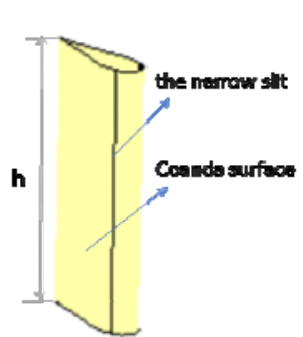

(a) the airfoil plate

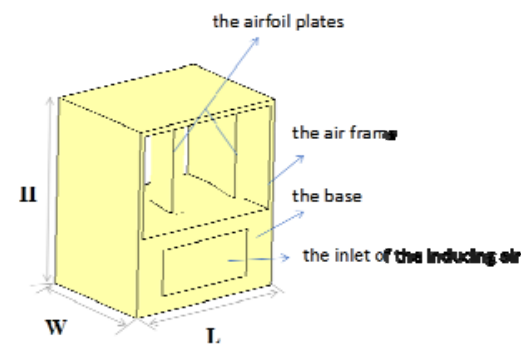

(b) the airfoil Ventilation Fan

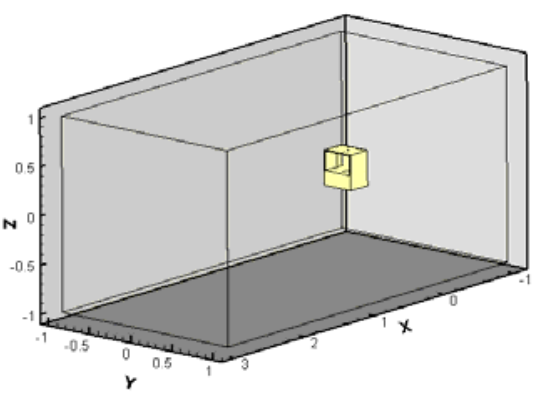

(c) the computational domain FIGURE I. PHYSICAL MODEL 


\section{B. Control Equations and Numerical Methods}

The control equations of the inducing airfoil ventilation fan are steady incompressible N-S equations, including continuous equation and motion equation. The standard $\kappa-\varepsilon$ turbulence model is chosen in this paper. Numerical methods are SIMPLE algorithm, which uses the most popular Fluent software is used to simulate to satisfy the equipment of the simulation.

\section{Boundary Conditions and Meshing}

The outlet of the narrow slits and the inlet of inducing air in the base of ventilation fan are all set as velocity-inlets, the boundary of the flow field in the large space is set as pressure-out, other external parts of the model are set to walls, which follow no slip boundary condition( $\mathrm{Ub}=0)$. Quad/Tri grids are used to mesh, the grids of the surrounding of Coanda curved surface and the narrow slits are got local encryption, which aims to ensure precision, computational efficiency and the demand of the computer's memory.

\section{RESULTS AND ANALYSIS}

A. The Analysis of the Flow Field about Inducing Airfoil Ventilation Fan

The inducing airfoil ventilation fan model whose inducing velocity $\left(\mathrm{V}_{0}\right)$ for short in the following content) is $25 \mathrm{~m} / \mathrm{s}$ is chosen to analyze. Fig 2 is the local 3-D streamline distribution and the streamline distribution of $\mathrm{Z}=0.1 \mathrm{~m}$, as shown in the Fig 2. Due to the operation of turbine, inducing air goes into the inside of ventilation fan through the inlet in the base. And inducing air can eject in a high-speed from narrow slit, flow the Coanda surface and induce the air located in the back of the model to flow along the direction of inducing air. At same time, the entrained air will increase in this process.

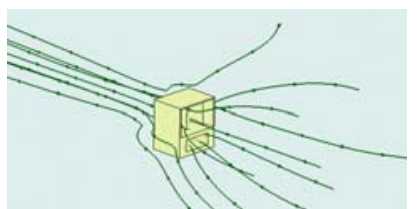

(a) the local 3-D streamline distribution

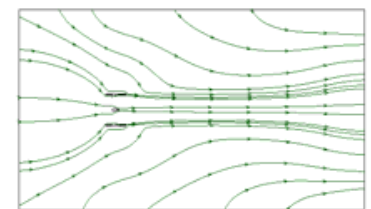

(b) the streamline distribution of $\mathrm{Z}=0.1 \mathrm{~m}$

FIGURE II. THE STREAMLINE DISTRIBUTION AT V0=15M/S

Comparison with different 3-D velocity iso-surfaces that the speeds in the flow field is $0.5 \mathrm{~m} / \mathrm{s}, 1 \mathrm{~m} / \mathrm{s}, 1.5 \mathrm{~m} / \mathrm{s}$ and $2 \mathrm{~m} / \mathrm{s}$ separately, as shown in the Fig 3 . The coverage area that the speed contour surface is $2 \mathrm{~m} / \mathrm{s}$ in flow field is least among these flowing four kinds of the speed contour surface, and the smaller velocity is, the further the speed contour surface develops. The air flow with the speed of $2 \mathrm{~m} / \mathrm{s}, 1.5 \mathrm{~m} / \mathrm{s}$ and $1 \mathrm{~m} / \mathrm{s}$ decays, the high-speed air flow can drive the air in the flow field, so it can decrease according to energy conservation law. The coverage area that the velocity of the air flow in the field is $0.5 \mathrm{~m} / \mathrm{s}$ enlarges along the positive $\mathrm{X}$ axis, the velocity decreases gradually from center to two sides in whole flow field.

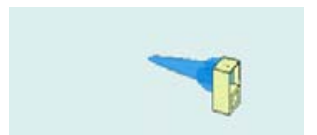

(a) $\mathrm{V}=2 \mathrm{~m} / \mathrm{s}$

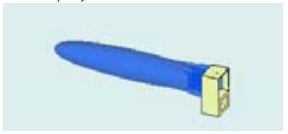

(c) $\mathrm{V}=1 \mathrm{~m} / \mathrm{s}$

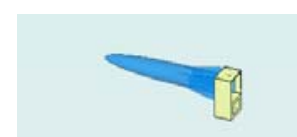

(b) $\mathrm{V}=1.5 \mathrm{~m} / \mathrm{s}$

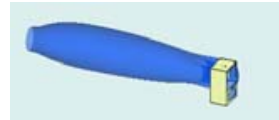

(d) $V=0.5 \mathrm{~m} / \mathrm{s}$
FIGURE III. THE X-VELOCITY CONTOUR SURFACES AT V0=15M/S

\section{B. Velocity Field}

In order to study the change laws of the velocity field and the induction rate in four different inducing velocities of $15 \mathrm{~m} / \mathrm{s}, 20 \mathrm{~m} / \mathrm{s}, 25 \mathrm{~m} / \mathrm{s}$ and $30 \mathrm{~m} / \mathrm{s}$, the velocity contour of $\mathrm{Z}=0.15 \mathrm{~m}$ is chosen to analyze, as shown in Fig 3 . With the inducing velocity increasing, the speed iso-surface develops further; the coverage area is larger and the number of the velocity contour become more. There is a low-speed area between adjacent airfoils, the main reason is the inducing air flow from narrow slits attaches the wall of airfoil plates, the position and the size of the low-speed area is almost unchanged in different inducing velocities.
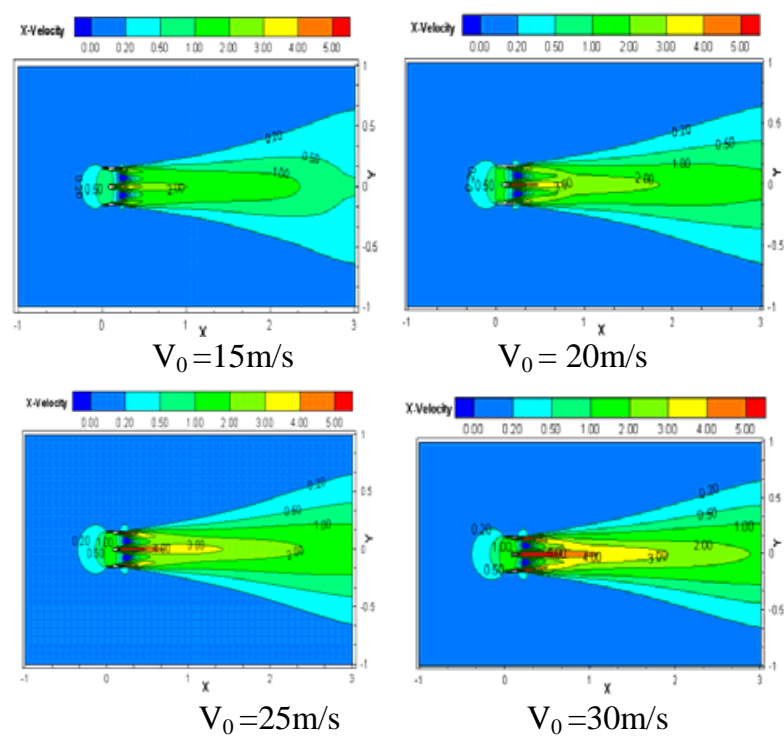

FIGURE IV. THE X-VELOCITY CONTOUR OF THE Z=0.15M IN DIFFERENT INDUCING VELOCITIES

\section{Inducing Rate}

Inducing rate is the specific value of the air quantity at a slice of $X$ axis and inducing air quantity. As shown in the Fig 4,the induction rate at the slice of $X=0.5, X=1, X=1.5, X=2$, $\mathrm{X}=2.5$ and $\mathrm{X}=3$ are analyzed, when the inducing velocities are $10 \mathrm{~m} / \mathrm{s}, 15 \mathrm{~m} / \mathrm{s}, 20 \mathrm{~m} / \mathrm{s}, 25 \mathrm{~m} / \mathrm{s}$ and $30 \mathrm{~m} / \mathrm{s}$ separately. With the inducing velocity increasing, the induction rate decreases, and the difference of induction rate at every slices would enlarge gradually along the positive $\mathrm{X}$ axis. When the inducing velocity is more than $25 \mathrm{~m} / \mathrm{s}$, the differences of the induction rate decrease in different inducing velocities, which approach a steady value finally. The phenomenon is caused by the extrusion between two strands of the high-speed airflow, the 
interference degree becomes stronger with the inducing velocity increasing.

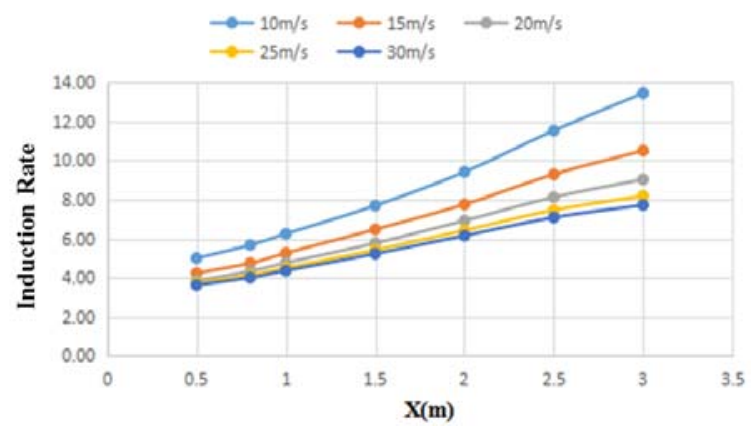

FIGURE V. THE INDUCTION RATES ALONG X AXIS IN DIFFERENT INDUCING VELOCITIES

\section{CONCLUSION}

1) Designing an airfoil ventilation fan based Coanda effect, which uses a few air volume to induce a large number of air volume and reaches the goal of energy saving.

2) When the size of a narrow slit remains unchanged, the induction rate along positive axis increases as the distance away from the narrow slits increasing, and approaching a steady value finally.

\section{REFERENCE}

[1] http://baike.so.com/doc/6807167-7024118.html.

[2] Shiyu ZHANG, et al. The study about the dynamic supercharging technique of circulation control airfoil(in Chinese).Nan Jing:Nanjing University of Aeronautics and Astronautics. (2011).

[3] Longzhe JIG, Nan MENG, Zhonglong LONG, et al. The numerical simulation study on the air curtain similar to air-knife in avoiding-disaster chamber(In Chinese). Journal of Safety Science and Technology, 2013.

[4] http://baike.so.com/doc/5394718-5631850.html.

[5] Hanxiang WANG, Min ZhAN, Haizhen XU, et al. Analysis and optimization on outlet of bladeless fan. Journal of Micromachined Fluid(In Chinese), 2013, 41(15):19-20.

[6] Guang xing ZHANG, et al. Study on the characteristic of flow field and air supply of bladeless fan (in Chinese)[D]. Hangzhou: Zhejiang Sci-TechUniversity, Dec.2013,Vol.9 No.12.

[7] Guoqi, Yongjun, Yingzi, et al. Influence of Coanda surface curvature on performance of bladeless fan[J]. Journal of Thermal Science, 2014, 23(5):422-431. 